\title{
Flood Alert System by using Weather Forecasting Data and Wireless Sensor Network
}

\author{
Sandeep Shiravale \\ Department of Information \\ Technology, \\ MIT Academy of Engineering, \\ Pune
}

\author{
Pranav Sriram \\ Department of Information \\ Technology, \\ MIT Academy of Engineering, \\ Pune
}

\author{
Sunil M. Bhagat \\ Department of Information \\ Technology, \\ MIT Academy of Engineering, \\ Pune
}

\begin{abstract}
This research proposal is basically for generating flood alert system in Indian environment by using weather forecasting data, and wireless sensor networks, The wireless sensor network is playing important role to transmission and monitoring the data, we can collect telemetered rainfall data and flow of water level data from various location, the system is measures the River Water Level, flow of water and different weather condition through wireless sensor network it also sends flood notification messages to the inhabitant of such a zones, base station of that area for necessary action.

The existing Indian flood alert system it's depend on Input data from satellites for flood forecasting, and it come after a long interval and some the information is quite insufficient. The designed system is based on WSN and it is used to monitor, detect and report the environment's status to a control unit using relative water level and amount of rainfall as flood indicators, whose values are gathered by sensors in the sensor field.
\end{abstract}

\section{Keywords}

Wireless Sensor Networks, Hydro meteorological, Zigbee

\section{INTRODUCTION}

The flood monitoring and detection system monitors and know the development of floods and then send flood notification SMS to the inhabitant of such zones for necessary action The objective of this project is to send the alert to riverside people so they can safely move from flood area it gives advanced alert through SMS The flood monitoring and detection system not only monitoring and alerting to the authorities \& uses but also it provides future predictions for the future disasters to the user.

We design a system with low-cost, small-sized, easily configurable and scalable WSN nodes to monitor, detect, and track various environmental phenomena and events.

\section{LITERATURE SURVEY}

\subsection{The Indian Context}

Flood is one of the major problems in India. It occurs mostly in some populated areas. This may be attributed to climate change which causes high rate of rainfall, placing many cities at increased risk of flooding as we aware during flash floods that kill more people than other natural disaster in an average a year, everyone is known during flood the peoples assets like roads, houses, farms etc. are destroyed and many people become homeless, it cause the millions of dollars of property damages and it will take lots of time to recover all the things flood warning is when an official announcement is given by radio or tv of an impending flood or an already flood that has already occurred. We are designing a system such a way the people can get the alert messages in advanced so they can move a safer location to save their life. The recent examples are disaster at a small village in Maharashtra and flood at kedar nath.

Wireless Sensor network can be deployed to monitor and detect flood in those areas. We get the input data from hydrometeorology flood forecasting [2]; sometime these data come after a long interval and may be quite insufficient. Therefore the need to have Wireless Sensor Networks (WSNs) monitored data such as water level, rainfall, and flow of water in river is essential in order to make a reasonable decision on the action necessary to detect flood. To effectively monitor and detect occurrence of flood in flood prone areas, monitoring and detection systems should be deployed to such areas to measure and record the required parameters. What makes a good monitoring system lies in the equipment used in the detection. Wireless Sensor Network is needful because it requires less energy, does not need hard wiring and can transmit data over a long distance [2].

Wireless Sensor Network consists of autonomous sensors to monitor physical or environmental conditions, such water level, rainfall and flow of water and to cooperatively pass their data through the network to a main location. WSNs are capable of sensing the real time data, process these data and transmit the measured data to the base station for further analysis and decision making [2]. It is therefore evident that the characteristics of WSNs include small size, integrated sensing, computational capabilities, low power communication [8].

\subsection{Rainfall Monitoring}

India receives 80 per cent of its annual rainfall during the southwest monsoon season of June to September. Rainfall over the country during this season shows a wide range of spatial variation due to geographic influences and preferential occurrence of rain-bearing systems in certain regions. India has a very extensive rain gauge network and rainfall monitoring over the country is a stupendous task. India is having Hydro meteorological Division of IMD they are monitoring daily the real time data of rainfall and preparing summaries data regularly even they are maintaining the data state wise and district wise. Maps showing weekly and cumulative rainfall figures in 36 meteorological subdivisions of the country are prepared. This information is very important to many user agencies, particularly for agricultural planning [1]. 


\subsection{Hydro meteorological Services}

IMD provides service like water management and river valley project management and this service is utilizing by Central Water Commission, Ministry of Water Resources and state government. Flood Meteorological Offices (FMOs) have been set up by IMD at different locations India. During the flood season, FMOs provide valuable meteorological support to the Central Water Commission for issuing flood warnings. Water balance studies are being conducted in respect of river basins by applying the well-known techniques of Thornthwaite for water budgeting and mass conservation principles [1].

\section{SYSTEM DESIGN AND IMPLEMENTATION}

We can get the all the information about environment from hydro meteorological service we can use these information for analysis for prediction of rainfall.

Our proposed flood monitoring and detection system will use sensor nodes installed in the sensor field for data collection, the parameters are transmitted via a multi-hop sensor network to the surveillance center. At the surveillance center, the data is received, processed and information concerning the flood status is then disseminated to the people in the affected geographical region via Short Message Service (SMS).

We design flood monitoring and detection system using water level, amount of rainfall, relative humidity as monitored variables for flood detection the amount of rainfall values are used to predict the water level. The water level will determine the extent of the flood as low, medium or high. This will enhance early flood detection. The flood status is sent directly to the occupants of the flood prone region directly from the base station. We designed a disaster and alert system using WSN to send weather information and disaster alerts by a Zigbee module [3]. This weather information was analyzed using decision tree techniques to announce the alerts. Proposed flood early warning system using SMS and web to record rainfall and water level data and SMS on flood status to attendants and stakeholders. The website can be accessed from anywhere.

The first level of implementation is to get the real time weather forecasting data of rainfall prediction form the hydro meteorological department the hydro meteorological department will provide the rainfall data, these data we can send to information process center.

In the second level of architecture we consider the data of current water level and flow of water in the riverside and wireless sensor network can transmit these data to Information Processing Center.

In the third level of implementation is we can collect the form hydro meteorological department i.e. rainfall data and data from base station i.e. the flow of water and water level data these data can be processes and finding the threshold level of the data.

In the Level fourth we need to get the processed the data from Information Processing Center and set the threshold if it is above threshold it will send a alert SMS to the riverside base station and riverside people in that flood area.

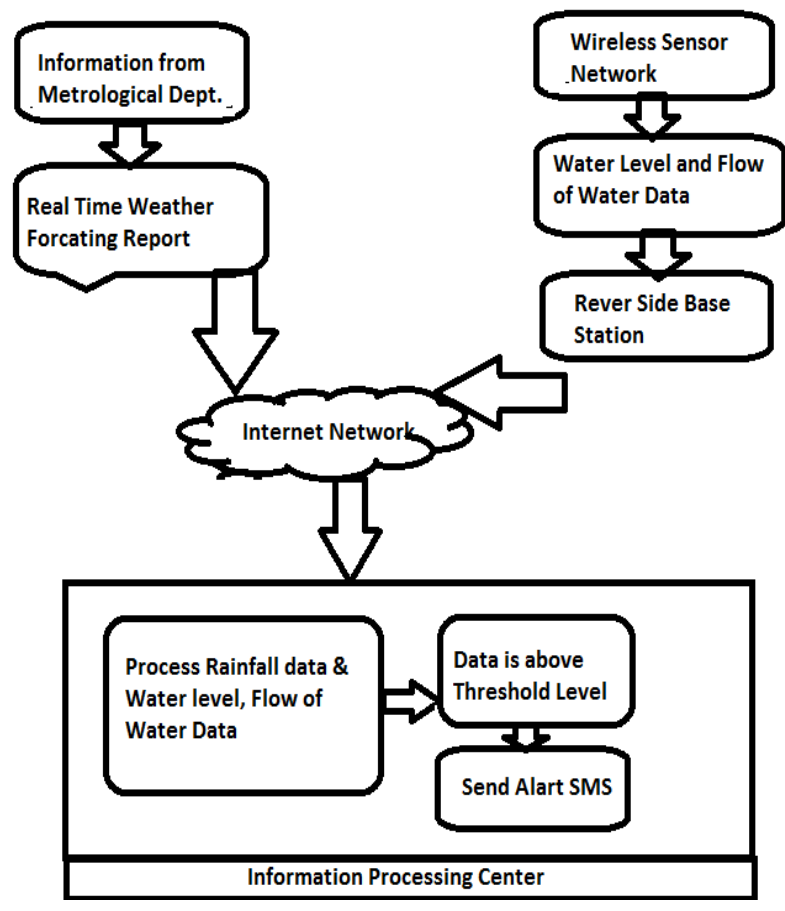

Fig 1: Architecture of Flood Alert System

\section{RELATED WORK}

\subsection{Information Processing Center:}

The data to be collected and compare the data includes the water level, the precipitation and the temperature and rainfall prediction. It is also capable to generate real time data and store in to database.

\subsection{Water Level Sensor \& Flow of Water}

The Base station of river side will maintain the water level and flow of water, we get the information from the riverside base station, the base station are using water level sensor and flow of water sensor the sensor will transmit these that through wireless sensor network

\subsection{Hydrological Services}

Hydrological department will provide a rainfall data and weather report, this department will provides us processed real time weather forecasting data these data we take as input to predict the how much rainfall will be there in particular region.

\subsection{Information Transmitting \& Receiving}

The important data transmission components consist of a hydrological data of rainfall, water level, flow of water. The parameter data is sent from the monitoring stations by GPRS modem and the GSM network to an FTP server in the data center. The system need to be configured before transmission can occurs. The parameter data is transferred to the FTP server via the mobile phone network immediately after recording by the sensors. If data cannot be sent due to traffic on the network or a low mobile signal level, it is stored in the database and sent later.

\subsection{Information Analysis and Processing}

The data is immediately sent from the FTP server to the application servers for processing to predict flooding and for real-time monitoring. For flood forecasting, the parameter data is processed by flood forecasting model software to make daily bulletins. For real-time monitoring, real-time graphs of water levels and to publish online. 


\section{CONCLUSION}

The system is used different sensor \& WSN technology for real-time data collection and transmission of water information from remote hydrological stations to the data center. The system is composed of five major components, data collection, data transmission, data receiving, data processing and information distribution. The flood monitoring and detection system monitors and know the development of floods and then send flood notification SMS to the inhabitant of such zones for necessary action. The main purpose of this project is to send alert to riverside people so they can safely move from flood area it gives advanced alert through SMS. We design a system with low-cost, small-sized, easily configurable and scalable WSN nodes to monitor, detect, and track various environmental phenomena and events. The main objective of this project work is to develop a real-time flood monitoring and warning system for a selected coastal area.

Table 1: Parameter of sensor component

\begin{tabular}{|l|l|l|}
\hline \multicolumn{1}{|c|}{ PARAMETER } & RANGE 0F VALUES & \multicolumn{1}{c|}{ STATUS } \\
\hline Relative Humidity $(\%)$ & $>=48.00$ & Very High \\
& $31.00-47.99$ & High \\
& $16.00-30.99$ & Low \\
\hline Minimum Temperature $\left({ }^{\circ} \mathrm{c}\right)$ & $25.00-28.99$ & Warm \\
& $24.00-24.99$ & Moderate \\
& $<=23.99$ & Low \\
\hline Maximum Temperature $\left({ }^{\circ} \mathrm{c}\right)$ & $>=33.00$ & Very hot \\
& $32.00-32.99$ & Hot \\
& $29.00-31.99$ & Warm \\
\hline Rainfall $(\mathrm{Mm})$ & $>=300.00$ & Heavy rainfall \\
& $\underline{101.00-299.99}$ & Moderate rainfall \\
& $<=100.99$ & Low rainfall \\
\hline Water Level $(\mathrm{M})$ & $>1.2$ & Very High \\
& $>0.81$ AND $<1.2$ & High \\
& $<0.8$ & Low \\
\hline
\end{tabular}

\section{REFERENCES}

[1] Basha, D. and Rus, D. "Design of Early Warning Flood Detection System for developing countries. Proceeding of the conference on Information and Communication Technologies and Development, Bonsalove, India.Pp 110,2007
[2] Kinny, P. "ZigBee Technology. Wireless Control that simply works". Proceedings of Communications Design Conference, WG, 2003

[3] Zigbee Alliance:"ZigBee Technology", March 2011 http://www.zigbee.org/about/about technology/zigbee technology.asp

[4] Windarto, J." Flood Early Warning System develop at Garang River Semarang using Information Technology base on SMS and Web". International Journal of Geomatics and Geosciences Vol. 1 No. 1, 2010

[5] A GPRS-Based Data Collection and Transmission for Flood Warning System: The Case of the Lower Mekong River Basin bye SaysothKeoduangsine and Robert Goodwin

[7] Wirawam, S., Pratoma, I., and Mita, Nagahisa. "Design of Low Cost Wireless Sensor Network-Based Environmental Monitoring System for Developing Country".Proceedings of APCC 2008.

[8] Seal, V., Raha, A., Maity, S., Mitra, S. K., Mukherjee, A. and Naskar, M. K. "A Simple Flood Forecasting Scheme Using Wireless Sensor Networks". International Journal of Ad hoc Sensor \& Ubiquitous Computing (IJASUC) Vol.3, No.1, pp. 45-60, 2012

[9] Blackmore, S.(1994). Precision Farming: An Introduction. Outlook on Agriculture 23(4) 4, 275-280.

[10] Ning Wang, Naiqian Zhang, Maohua Wang, "Wireless sensors in agriculture and food industry-Recent development and future perspective", published in Computers and Electronics in Agriculture 50 (2006) 114.

[11] Akyildiz, I.F., Xudong Wang: A Survey on Wireless Mesh Networks, IEEE Communications Magazine (September 2005)

[12] AZoNanotechnology Article: "Precision Agriculture Nanotech Methods Used, Such as 'Smart Dust', Smart Fields' and Nanosensors:"

[13] "SoilNet - A Zigbee based soil moisture sensor network" Project Group, Institute Of Chemistry And Dynamics Of The Geosphere (ICG), Agrosphere Institute, ICG 4, Forschungszentrum Jülich GmbH, 52425 Jülich,

[14] IEEE Std. 802.15.4-2003, Wireless Medium Access Control (MAC) and Physical Layer (PHY) Specifications for Low Rate Wireless Personal Area Networks (2003 